\title{
Evaluation of two doses of ceftiofur crystalline free acid sterile suspension for treatment of metritis in lactating dairy cows
}

\author{
C. L. McLaughlin, ${ }^{1}$ E. Stanisiewski, M. J. Lucas, C. P. Cornell, J. Watkins, ${ }^{2}$ L. Bryson, ${ }^{3}$ J. K. S. Tena, \\ J. Hallberg, and J. R. Chenault \\ Pfizer Animal Health, 333 Portage Street, Kalamazoo, MI 49001
}

\section{ABSTRACT}

The objectives of this study were to evaluate efficacy of a 2-dose regimen of ceftiofur crystalline free acid sterile suspension (CCFA-SS) for treatment of acute metritis in lactating dairy cows under field conditions and to provide additional safety and injection site tolerance data for injections at the base of the ear. Cows at 15 dairies with rectal temperature $\geq 39.5^{\circ} \mathrm{C}$ and fetid uterine discharge $\leq 10 \mathrm{~d}$ postcalving were randomly assigned by blocks of 2, based on order of entry and without regard to parity, to treatment with saline (1.5 $\mathrm{mL} / 45.5 \mathrm{~kg}$ of body weight, $\mathrm{n}=509)$ or CCFA-SS (6.6 $\mathrm{mg}$ of ceftiofur equivalents $/ \mathrm{kg}$ of body weight, $\mathrm{n}=$ 514). Treatments were administered by subcutaneous injection in the posterior aspect of the ear where it attaches to the head; the first dose was administered on study d 0 and the second dose was administered in the contra lateral ear on study d 3. Rectal temperatures were recorded on study d 1 to 4 and 5 or 6 and cows were clinically evaluated daily from study d 1 to 13 . Cows that exhibited increased adverse clinical signs of poor health or complications associated with metritis were categorized as a treatment failure and administered escape therapy. Each cow received a veterinary physical examination on study d 5 or 6 to determine if she should be removed from the study and on study $d$ 14 to determine clinical cure or failure to cure. Clinical cure was defined as rectal temperature $<39.5^{\circ} \mathrm{C}$ and non-fetid and purulent or mucopurulent discharge on study d 14 and no escape therapy administered. The injection procedure was scored after each injection (study d 0 and 3) and injection sites and ear carriage were scored on study d 5 or 6,14 , and $57 \pm 3$. Of the 1,023 cows enrolled, 7 were completely censored due to protocol deviations and 34 were removed for protocol deviations or medical conditions not related to metritis.

\footnotetext{
Received October 31, 2011.

Accepted April 14, 2012.

${ }^{1}$ Corresponding author: carol.mclaughlin@pfizer.com

${ }^{2}$ Current address: Midwest Veterinary Services, Oakland, NE 68045.

${ }^{3}$ Current address: Boehringer-Ingelheim Vetmedica, St. Joseph, MO 64506 .
}

Clinical cure rate was higher for CCFA-SS than for saline (74.3 vs. $55.3 \%)$ and rectal temperatures for each of study d 1 to 5 or 6 were lower for CCFA-SS than saline. Injection procedure indices showed that CCFASS could be practically and safely administered using commercial dairy facilities. Although injection site scores were higher for CCFA-SS than saline at study d 5 or 6 and $14, \geq 98.6 \%$ of ears were normal on $\mathrm{d} 57 \pm$ 3. Thus, a 2-dose treatment with CCFA-SS given $72 \mathrm{~h}$ apart increased metritis clinical cure rate and was well tolerated in dairy cows.

Key words: acute metritis, ceftiofur, dairy cow

\section{INTRODUCTION}

Acute post parturient metritis (acute metritis; also known as acute puerperal metritis) is a common disease of dairy cows and is associated with significant economic losses because of the sequelae of reduced milk production, poorer reproductive performance, and increased risk of culling (LeBlanc et al., 2002; Overton and Fetrow, 2008; Wittrock et al., 2011). Sheldon et al. (2006) have defined puerperal metritis as an abnormally enlarged uterus and a fetid watery red-brown discharge associated with signs of systemic illness (decreased milk yield, dullness, or other signs of toxemia) and fever (temperature $>39.5^{\circ} \mathrm{C}$ ) within $21 \mathrm{~d}$ after calving. The reported incidence of metritis ranges widely from 10 to $36 \%$ in dairy cows (Stevenson and Call, 1988; Borsberry and Dobson, 1989; LeBlanc et al., 2002) and a $21 \%$ incidence rate of metritis during lactation was found in a large survey including 97,316 cows with 181,322 lactations (Zwald et al., 2004).

Specific bacteria identified in the uterus of dairy cattle with metritis include Escherichia coli, Arcanobacterium pyogenes, Fusobacterium necrophorum, Prevotella spp., and Bacteroides spp. (Huszenicza et al., 1999; Sheldon et al., 2004b; Bicalho et al., 2011). Sheldon et al., (2004a), using 20 to 22 strains of bacteria isolated from uteri of postpartum cows with pyrexia and or metritis determined $\mathrm{MIC}_{90}$ [minimum concentration (in vitro) that will inhibit $90 \%$ of the strains of the organism tested] values for 6 antibiotics used to treat 
metritis; $\mathrm{MIC}_{90}$ values for ceftiofur were $0.5 \mu \mathrm{g} / \mathrm{mL}$ for E. coli and $0.125 \mu \mathrm{g} / \mathrm{mL}$ for both $A$. pyogenes and $F$. necrophorum. Thus, metritis treatments include the use of systemic antibiotics, specifically cephalosporins (Zhou et al., 2001; Chenault et al., 2004) and uterine antimicrobial boluses (Smith et al., 1998; Drillich et al., 2001) to maintain concentrations above the $\mathrm{MIC}_{90}$ values for the specific pathogens.

Treatment of cows having a rectal temperature $\geq 39.5^{\circ} \mathrm{C}$ within $10 \mathrm{~d}$ of calving with $1-\mathrm{mg}$ ceftiofur equivalents (CE) of ceftiofur sodium or chloride per kilogram of $\mathrm{BW}$ for $3 \mathrm{~d}$ increased cure rate of cows that also had a vaginal discharge at enrollment compared with saline-treated controls (56.0 vs. $28.9 \%$, respectively; Zhou et al., 2001). In addition, cows with toxic puerperal metritis treated with $600-\mathrm{mg} \mathrm{CE}$ of ceftiofur hydrochloride (approximately 1-mg $\mathrm{CE} / \mathrm{kg}$ of $\mathrm{BW}$ ) given i.m. for $3 \mathrm{~d}$ with or without intrauterine antibiotics $(2,500 \mathrm{mg}$ of ampicillin and $600 \mathrm{mg}$ of cloxacillin) were equally responsive in terms of rectal temperature and reproductive performance as cows given $600 \mathrm{mg}$ of ampicillin i.m. and intrauterine antibiotics (Drillich et al., 2001). In cows enrolled $<14 \mathrm{~d}$ postpartum with rectal temperature $\geq 39.5^{\circ} \mathrm{C}$ and fetid vaginal discharge, treatment for $5 \mathrm{~d}$ with $2.2-\mathrm{mg} \mathrm{CE}$ of ceftiofur hydrochloride $/ \mathrm{kg}$ of BW increased clinical cure rate at $14 \mathrm{~d}$ compared with controls (77 vs. $62 \%$ ), whereas one-half the dose of CE given for $5 \mathrm{~d}$ did not have a significant effect on clinical cure rate in this US study (Chenault et al., 2004). The effects of treatment with 2.2-mg CE of ceftiofur sodium $/ \mathrm{kg}$ of BW administered i.m. for 5 d to cows with toxic puerperal metritis on rectal temperature on $\mathrm{d} 1$ and 5 and milk yield on $\mathrm{d} 1$ to 12 were similar to those of treatment with 22,000 IU of procaine penicillin $/ \mathrm{kg}$ of BW i.m. for $5 \mathrm{~d}$, with or without an intrauterine infusion of $6 \mathrm{~g}$ of oxytetracycline on $\mathrm{d} 1,3$, and 5 (Smith et al., 1998).

In pharmacokinetic studies, 1-mg CE of ceftiofur hydrochloride $/ \mathrm{kg}$ of $\mathrm{BW}$ administered for 1 (Okker et al., 2002) or $3 \mathrm{~d}$ (Drillich et al., 2006) resulted in concentrations of ceftiofur derivatives in serum, lochial fluid, endometrium, and caruncles $24 \mathrm{~h}$ after the last injection that were higher than the $\mathrm{MIC}_{90}$ values reported for E. coli, F. necrophorum, and A. pyogenes, the pathogens associated with metritis. It was clear from the rate of decrease in the concentrations in uterine tissues that daily injections would be required to maintain concentrations above $\mathrm{MIC}_{90}$ levels.

However, successfully delivering daily injections for extended periods requires excellent management practices in a commercial dairy setting. In a recent survey of 113 dairy herds in Pennsylvania, only $24 \%$ of producers completed the treatment protocol per label for a given condition (Sawant et al., 2005). Ceftiofur crystalline free acid sterile suspension (CCFA-SS; EXCEDE; Pfizer Animal Health Inc., New York, NY; http://pfizerah.com) is approved in the United States for the treatment of bovine respiratory disease and foot rot when administered as a single dose of $6.6-\mathrm{mg} \mathrm{CE}$ of CCFA-SS $/ \mathrm{kg}$ of BW.

It was hypothesized that treatment of metritis with a single dose of CCFA-SS would be more convenient than 5 daily injections of ceftiofur hydrochloride (Excenel RTU; Pfizer Animal Health Inc.; http://pfizerah.com) and would increase clinical cure rate compared with negative controls. However, in a large field trial in the United States with similar design as used in the current study, a single dose of CCFA-SS did not increase the metritis cure rate (J. R. Chenault and M. J. Lucas; unpublished data). In addition, it was found that concentrations of ceftiofur derivatives in both caruncle and endometrial tissue $3 \mathrm{~d}$ after a single dose of CCFA-SS were less than $0.5 \mu \mathrm{g} / \mathrm{g}$ (M. A. Yancey, J. A. Robinson, M. J. Lucas, M. J. Prough, W. L. Bryson, Pfizer Animal Health, Kalamazoo, MI; personal communication), the $\mathrm{MIC}_{90}$ for E. coli (Sheldon et al., 2004a). Thus, 2 doses of CCFA-SS administered $72 \mathrm{~h}$ apart were postulated to effectively increase clinical cure rate due to extended duration of levels of ceftiofur above effective $\mathrm{MIC}_{90}$ levels for bacteria associated with metritis. Thus, a trial was conducted to evaluate both the efficacy and safety of 2 doses of CCFA-SS given $72 \mathrm{~h}$ apart to cows with clinical signs of metritis. The injection procedure and injection site information were included as measures of safety because this was the first registration trial in dairy cows in which the route of injection of CCFA-SS was the base of the ear.

\section{MATERIALS AND METHODS}

All aspects of this study were performed to meet the Food and Drug Administration-Center for Veterinary Medicine (FDA-CVM) Good Clinical Practice guide (FDA-CVM, 2009), except where noted otherwise and was conducted under the authorization of Investigational New Animal Drug (INAD) 10-978. The trial was conducted in a manner consistent with applicable local, state, and federal laws and regulations governing humane care of animals on commercial farms under veterinary supervision.

\section{Treatments and Experimental Design}

The study was conducted as a multi-dairy randomized design with cows blocked by order of entry within dairy without regard to parity. The objective was to 
evaluate the effectiveness of a 2-dose treatment regimen of CCFA-SS in cows with acute metritis compared with saline-treated controls. Using a 2-sided test at the 0.05 significance level for a treatment comparison, there was an expected $80 \%$ power to detect a 10 -percentage point difference in clinical cure rate using the assumptions of $50 \%$ clinical cure rate in the saline control group, with 15 locations and 30 animals in each of 2 treatment groups at each location included in the statistical analysis for effectiveness. Cows meeting enrollment criteria were assigned to treatment and ear to receive first injection in blocks of 2 without regard to parity. Treatments were saline $(1.5 \mathrm{~mL}$ of sterile saline for injection/45.5 kg of BW) or CCFA-SS [1.5 mL of $200-\mathrm{mg}$ $\mathrm{CE} / \mathrm{mL}$ of CCFA-SS per $45.5 \mathrm{~kg}$ of BW (6.6-mg CE/ $\mathrm{kg}$ of BW); Pfizer Animal Health Inc.; http://pfizerah. com]. All personnel at each site who were involved in the study, except the treatment administrator, were blinded to treatment and the treatment administrator performed no other study-related activities.

\section{Cows and Enrollment}

Cows from 15 commercial dairies located throughout the United States were included in the study from June through October, 2006. The rectal temperature (GLA M700 thermometer with M207 probe; GLA Agricultural Products, San Luis Obispo, CA; http:// www.gla-ag.com) of all potentially eligible cows that had calved at each study location through $10 \mathrm{~d}$ postcalving (from d 1 to 10 postcalving) was determined daily each morning. Electronic medical histories (e.g., Dairy Comp 305, DHIA Plus) of cows with rectal temperatures $\geq 39.5^{\circ} \mathrm{C}$ were reviewed to determine that cows did or did not meet exclusion criteria. Exclusion criteria were (1) administration, since calving, of any product containing antimicrobial (other than topical), steroidal, or nonsteroidal antiinflammatory, estrogenic, antipyretic, oxytocin, or prostaglandin agents; (2) administration of antimicrobials other than topical during the $14 \mathrm{~d}$ immediately before parturition; (3) caesarian section delivery, fetotomy, or uterine prolapse at the most recent calving; and (4) retained fetal membranes and treatment with antimicrobials by either intrauterine or parenteral routes at the most recent calving. The investigator evaluated vaginal discharge present on the rear of the animal and if none was present, a sample of discharge was obtained using a gloved hand in the vagina or use of a Metricheck device (Simcro, Hamilton, New Zealand; http://www.simcro.com) and determined the vaginal discharge score using the following scoring system: $0=$ no discharge observed; $1=$ not fetid, normal lochia, viscous, red, brown, or clear; 2
$=$ not fetid, thick mucus, cloudy, clearing, or clear; $3=$ not fetid, may be purulent or mucopurulent, chocolate brown; and $4=$ fetid, thin, serous, or watery, may have been red/pink (tomato soup) to chocolate brown, with or without pieces of necrotic tissue present. Cows with a vaginal discharge score of 4 were subjected to a physical exam conducted by a veterinarian to determine if conditions were present that might cause elevated rectal temperature or affect the response to treatment such as vaginal tears, traumatic gastritis, gastroenteritis, displaced abomasum, hemorrhagic septicemia, complicated pneumonia, or laminitis. Assigned treatment was administered by s.c. injection in the posterior aspect of the ear where it attaches to the head (base of the ear) with the first dose administered on study d 0 and the second dose administered in the contra lateral ear on study d 3. To determine dose volume of saline or CCFA-SS, the BW of each cow was estimated using a breed-specific heart girth measuring tape (Nasco Inc., Atkinson, WI).

\section{Measurements}

Postinjection Indices. Immediately after injection, the treatment administrator evaluated the injection process using 3 indices: animal restraint, injection procedure index, and postinjection problem index. The scoring system for animal restraint was $0=$ normal, injection administered without additional restraint (normal restraint consisted of procedures routinely used for injection into the jugular vein, such as neck lock-ups plus use of a halter or nose leads/tongs, among others) or $1=$ additional restraint required. The scoring system for the injection procedure was $0=$ normal or $1=$ required reinjection, due to animal movement (the needle needed to be re-inserted into the base of the ear). The scoring system for the postinjection problem was $0=$ none, $1=$ bleeding, $2=$ leak back of injected material, $3=$ bleeding and leak back of injected material, and $4=$ other.

Rectal Temperatures and Daily Observations. Rectal temperatures were measured before noon at the same time of day, specific for each dairy, on study d 1 , 2,3 , and 4 . Cows were observed daily from study d 1 to 13 for abnormal clinical signs (e.g., dehydration, anorexia, weakness, or severe depression) and the investigator was notified of animals showing these signs. Some therapies including fluid supportive therapies of sodium chloride, dextrose, propylene glycol, Ringer's lactate, among others, could be administered at any time without removing animals from the study. Local anesthetics and topical antimicrobials could be administered for minor surgical repairs of wounds or teat surgeries and 
calcium supplementation was permitted for cows with a diagnosis of milk fever. Animals that developed conditions secondary to acute postpartum metritis, such as mastitis, displaced abomasum, and ketosis could receive supplemental therapy as follows and remained in the study and were not considered treatment failures. Mastitis could be treated only by frequent milkings. Displaced abomasum could be treated surgically and or with laxatives; topical antimicrobials could be used, but only regional anesthesia (e.g., line block) could be used if treated surgically. Ketosis could be treated with propylene glycol, dextrose, and B vitamins as needed. Dexamethasone or Predef Sterile Suspension or Sterile Solution (Predef SS, isoflupredone acetate; Pfizer Animal Health Inc.; http://pfizerah.com) could be administered, if needed, following label dosing directions. Dexamethasone could be administered only once and Predef SS could be administered only twice. However, neither dexamethasone nor Predef SS was permitted to be administered on d 11 to 14 . Animals requiring more aggressive treatments were declared treatment failures and escape therapy was administered.

Physical Examinations. Physical examinations were conducted by a veterinarian on study d 5 or 6,14 , and $57 \pm 3$. On study d 5 or 6 , rectal temperature and vaginal discharge score were recorded and, based on this information, the veterinarian determined if the cow was to remain in the study or be declared a treatment failure so that escape therapy could be administered. Criteria for removal included declining physical or clinical condition such as dehydration, anorexia, weakness, severe depression, or any other clinical signs attributable to toxic metritis with or without associated persistent rectal temperature $\geq 39.5^{\circ} \mathrm{C}$. Cows with a rectal temperature $\geq 39.5^{\circ} \mathrm{C}$ or a vaginal discharge score of 4 could not be removed without additional clinical signs. Cows removed from the study received escape therapy, and had an exit examination which documented reason for removal.

On study d 14, rectal temperature and vaginal discharge score were determined for each cow that remained in the study and were not considered treatment failures. Once during study d $57 \pm 3$ a clinical evaluation of normal or abnormal was made for each surviving cow; any observation of abnormal was described.

Injection Site Evaluations. On study d 5 or 6, 14, and $57 \pm 3$, ears of all surviving cows were evaluated, including cows previously removed from the efficacy portion of the study (study d 1 to 14) after physical examinations. The site of injection at the base of each ear and the adjacent facial and auricular muscles within an approximate $2.5-\mathrm{cm}$ radius of the injection site were observed and palpated and the following scoring system was used to evaluate injection sites: $0=$ normal, no swelling or fluid detected; $1=$ swelling or fluid, well defined, 2.5 to $5 \mathrm{~cm}$ in diameter detected; $2=$ swelling or fluid, well defined, greater than $5 \mathrm{~cm}$ in diameter detected; 3 = diffuse swelling or fluid detected; $4=$ ruptured, draining wound; and $5=$ other. In addition, the carriage of each ear was also observed and scored as either normal or dropped (droopy).

Study d 14 to $57 \pm$ 3. After the physical examination on study d 14 was completed, cows were subjected to the normal herd health program at each study location and all medical interventions were documented. The only reasons cows could be removed from the study during this period were for death or euthanasia. In event of death, a necropsy was conducted.

\section{Statistical Analysis}

Clinical Cure Rate. Clinical cure rate, the measure of treatment efficacy, was based on information collected on study d 14. Clinical cure was defined as rectal temperature $<39.5^{\circ} \mathrm{C}$, vaginal discharge score $\leq 3$ (not fetid), and no escape therapy administered. A failure to cure was defined as temperature $\geq 39.5^{\circ} \mathrm{C}$ or vaginal discharge score $=4$ (fetid), or both, or administration of escape therapy. In addition, animals that died or were moribund due to acute metritis were considered failures to cure. For statistical analysis, each animal was assigned a value of 0 (failure) or 1 (clinical cure). Animals that received concomitant antimicrobial or antiinflammatory therapy administered for a condition not related to acute metritis; animals that died, were euthanized, or culled for a condition not related to acute metritis; or animals that were associated with a deviation from protocol were censored from the efficacy analysis. Clinical cure rate was analyzed using a generalized linear mixed model (GLMM); the macro GLIMMIX in SAS (SAS Institute, 2003) was used with a binomial error and logit link. Within this model, treatment was the fixed effect, whereas dairy farm, treatment by dairy farm, and residual were random effects. The analysis used the penalized quasi-likelihood approach with restricted maximum likelihood estimation of the variance components. Efficacy was determined by comparing the CCFA-SS group with the saline group at a 2 -sided significance level of 0.05 .

Rectal Temperatures. Rectal temperatures during study d 0 to 5 or 6 were analyzed using a repeated measures ANOVA (SAS Institute, 2003). The model included treatment, time, and treatment by time as fixed effects. The random effects included dairy farm, dairy farm by treatment, between-animal error, and dairy farm by treatment by time. The variance-covariance structure of the repeated measures was fit to at least the following models: compound symmetry, heteroge- 
neous compound symmetry, and unstructured. The unstructured model had the best Akaike information criterion and was chosen as the final model.

Injection Site and Ear Carriage Scores. Ear injection site and ear carriage scores were summarized by study day ( 5 or 6,14 , or $57 \pm 3$ ), within treatment group (CCFA-SS or saline) and by side injected (first and second). The percent normal scores were analyzed by side injected using a generalized linear mixed model with a binomial error and logit link (PROC GLIMMIX, SAS 9.2; SAS Institute, 2009). The fixed effects in the model were treatment, time, and treatment by time interaction. The random effects were dairy farm, dairy farm by treatment, between-animal error, and dairy farm by treatment by time.

Animal Restraint Index, Injection Procedure Index, and Postinjection Problem Index. Animal restraint index, injection procedure index, and postinjection problem index were summarized by treatment group (CCFA-SS or saline) and by side injected (first and second). The percent normal restraint, normal injection procedure, and no postinjection problem were analyzed by side injected using a generalized linear mixed model with a binomial error and logit link (PROC GLIMMIX, SAS 9.2; SAS Institute, 2009). The fixed effect was treatment and random effects were dairy farm and dairy farm by treatment.

Adverse Events. The number of animals having an adverse event and total number of events were summarized by event category and treatment. The percent of animals ever having any adverse event was analyzed using a generalized linear mixed model with binomial error and logit link (PROC GLIMMIX, SAS 9.2; SAS Institute, 2009). The fixed effect was treatment and random effects were dairy farm and dairy farm by treatment. The number of adverse events per animal was $\log$ transformed $[\operatorname{Ln}(\mathrm{X}+1)]$ and analyzed using a general linear mixed model. The fixed effect was treatment and random effects were dairy farm, dairy farm by treatment, and residual.

\section{RESULTS}

Enrollment was discontinued at 2 sites at the same week that enrollment was completed at the last of the remaining 13 study sites because the expected calving rates indicated that it would be weeks to several months before the full 70 cows would be enrolled. The remaining 13 clinical sites each enrolled between 33 and 37 cows per treatment group for a total of 1,023 cows. Seven cows were completely censored from all statistical analyses and data summaries due to deviations to the protocol. Deviations included items such as missed physical exams and incorrect treatment or treatment

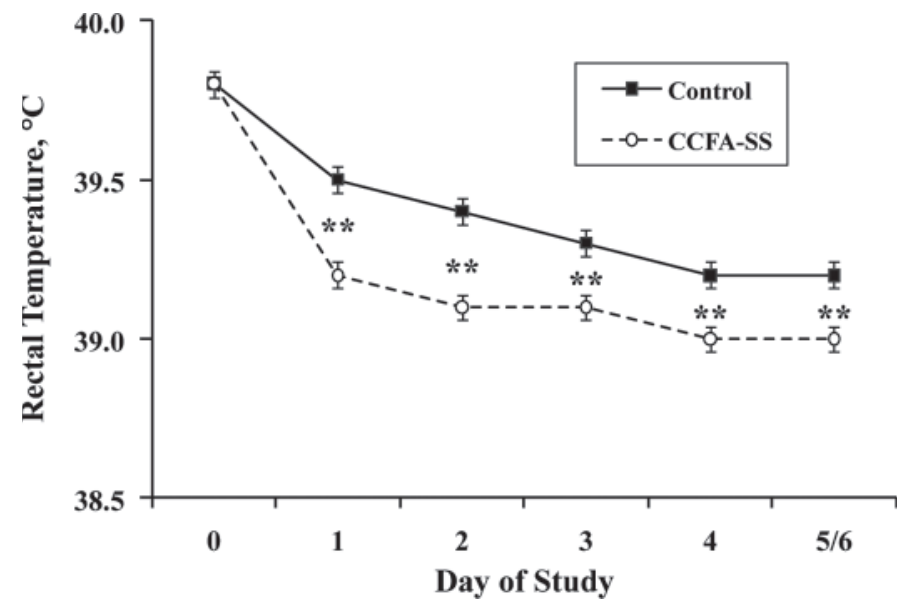

Figure 1. Average rectal temperatures (LSM \pm SEM) for study d 0 to 5 or 6 after enrollment for cows treated with $1.5 \mathrm{~mL}$ of saline/45.5 $\mathrm{kg}$ of BW or 6.6-mg ceftiofur equivalents (CE) of ceftiofur crystalline free acid sterile suspension (CCFA-SS) $/ \mathrm{kg}$ of BW. Effect of treatment: $P<0.0001$, day of study: $P<0.0001$, and treatment by day of study: $P<0.0001$. ${ }^{* *}$ CCFA-SS was different from saline within day $(P \leq$ $0.0003)$.

dose administration. Another 34 cows were removed from the statistical analysis for effectiveness due to deviations from the protocol or for a medical condition (adverse event) not related to metritis.

Clinical cure rate was greater $(P<0.0001)$ for cows administered CCFA-SS than for cows administered saline ( 74.3 vs. $55.3 \%$ back-transformed LSM). Significant effects of treatment, day, and treatment by day interaction on rectal temperature were observed (Figure 1). The rectal temperature of cows administered CCFA-SS was lower $(P \leq 0.0003)$ than that of cows administered saline on each of study d 1 to 5 or 6 .

Normal restraint equipment was adequate to inject treatments at the base of the ear for $\geq 98.8 \%$ of both first and second injections and no difference $(P \geq 0.62)$ existed between percentage normal restraint for animals administered CCFA-SS compared with saline (Table 1). In addition, $\geq 97.1 \%$ of both first and second injections (saline and CCFA-SS) were made without need for reinjection due to animal movement and no difference $(P$ $\geq 0.16$ ) existed between percentage normal injection procedure for animals administered CCFA-SS compared with saline (Table 1). The postinjection problem index categories were none, bleeding, leak back of injected material, both bleeding and leak back, or other. No postinjection problems $($ score $=0$ ) were observed in $\geq 85.8 \%$ of all doses administered (Table 1 ) and no difference existed in percentage of no postinjection problem between CCFA-SS and saline $(P \geq 0.3445)$.

Percentages of normal injection site scores are presented in Table 2. Statistical differences existed between 
Table 1. Percentages ${ }^{1}$ of normal $($ score $=0$ ) animal restraint index scores, injection procedure index scores, and postinjection problem index scores for cows treated with $1.5 \mathrm{~mL}$ of saline/45.5 $\mathrm{kg}$ of $\mathrm{BW}$ or $6.6-\mathrm{mg}$ ceftiofur equivalents (CE) of ceftiofur crystalline free acid sterile suspension $\left(\mathrm{CCFA}-\mathrm{SS}^{2}\right) / \mathrm{kg}$ of BW

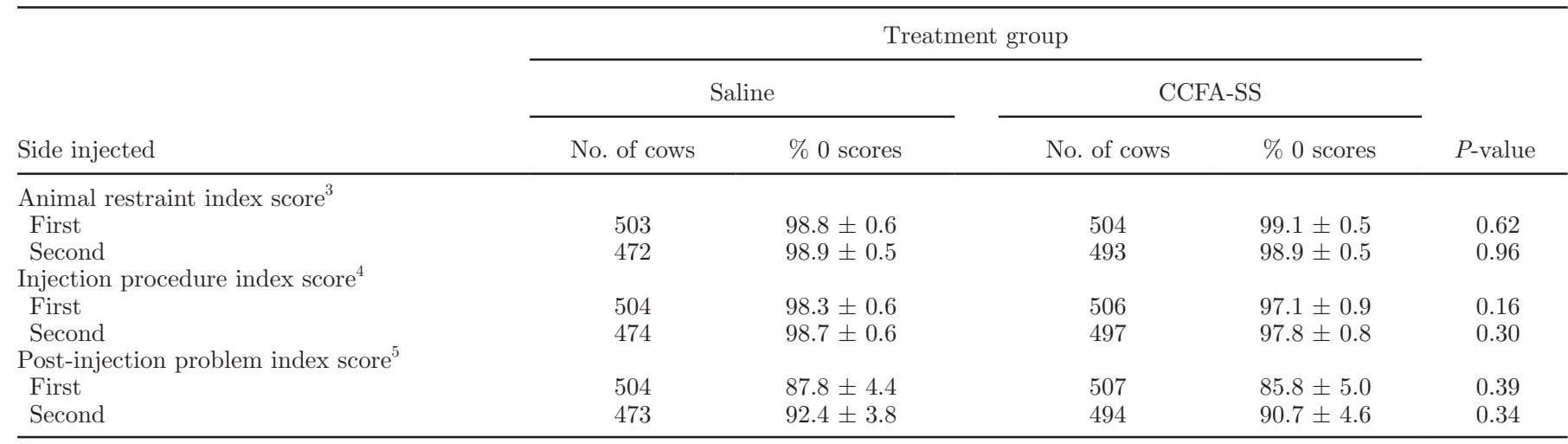

${ }^{1}$ Back-transformed LSM \pm SEM.

${ }^{2}$ Pfizer Animal Health, New York, NY.

${ }^{3}$ Animal restraint index score: $0=$ normal restraint; $1=$ additional restraint needed.

${ }^{4}$ Injection procedure index score: $0=$ normal; 1 = reinjection needed due to animal movement.

${ }^{5}$ Postinjection problem index score: $0=$ none; 1 = bleeding; 2 = leak back of injected material; 3 = bleeding and leak back of injected material; $4=$ other.

treatments $(P \leq 0.0004)$ and study day $(P \leq 0.0001)$ for both the first and second injection, which were analyzed separately. For the second day of injection, the interval to observation was 2 or $3 \mathrm{~d}$ for study d 6 and $11 \mathrm{~d}$ for study d 14. Percentages of normal injection site scores were less $(P \leq 0.0028)$ for CCFA-SS than saline for both first and second injections on study d 5 or 6 and 14. By d $57 \pm 3$, percentage normal injection site scores after both the first or second injection did not differ $(P \geq 0.27)$ between CCFA-SS and saline.

Percentages of normal ear carriage scores are summarized in Table 3 . No differences $(P \geq 0.070)$ were observed in percentages of normal scores between CCFA-SS and saline at any time point.

One cow died immediately (15-20 min) following administration of a second dose $(19 \mathrm{~mL})$ of CCFA-SS. Necropsy results led to the conclusion that the probable cause of death was intraarterial injection of CCFA-SS. Adverse health events not related to acute metritis are summarized by general category and treatment group in Table 4. Independently of event category, the number of cows that had an adverse event and the number of adverse events per cow did not differ between treatment groups $(P \geq 0.11)$.

Table 2. Percentages of normal ${ }^{1}($ score $=0$ ) ear injection site scores for the first and second injected ear of cows treated with $1.5 \mathrm{~mL}$ of saline/45.5 kg of BW or 6.6-mg ceftiofur equivalents (CE) of ceftiofur crystalline free acid sterile suspension $\left(\mathrm{CCFA}^{\left.-\mathrm{SS}^{2}\right) / \mathrm{kg} \text { of BW }}{ }^{3}\right.$

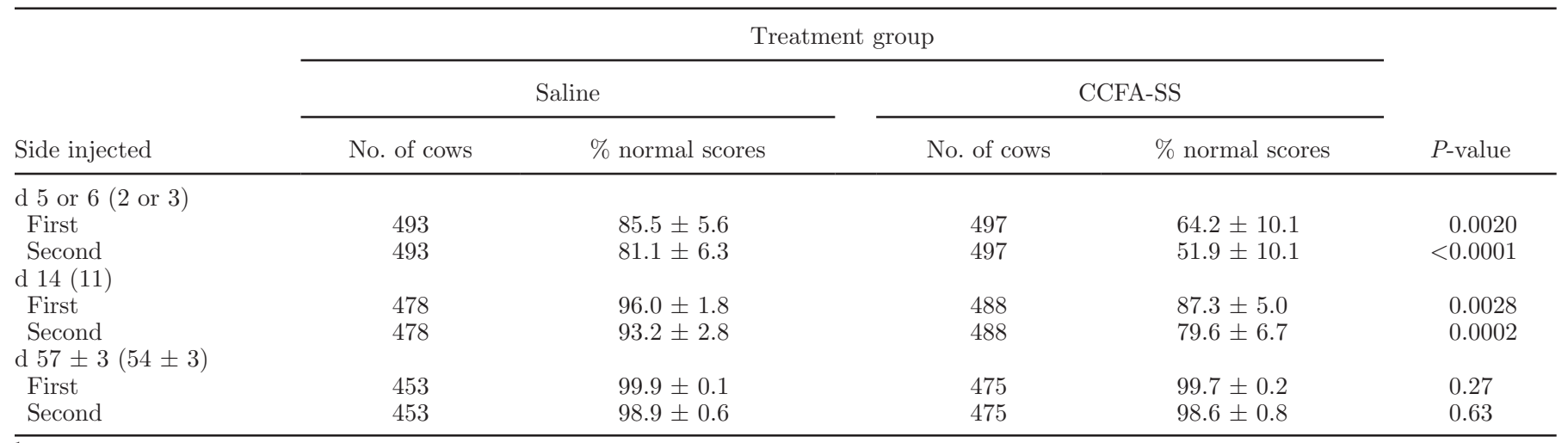

${ }^{1}$ Back-transformed LSM \pm SEM.

${ }^{2}$ Pfizer Animal Health, New York, NY.

${ }^{3}$ Numbers in parentheses are the days between administration of the second dose and the observation. 
Table 3. Percentages of normal ${ }^{1}$ (score $=0$ ) ear carriage scores for the first and second injected ears of cows treated with $1.5 \mathrm{~mL}$ of saline/45.5 $\mathrm{kg}$ of BW or $6.6-\mathrm{mg}$ ceftiofur equivalents $(\mathrm{CE})$ of ceftiofur crystalline free acid sterile suspension $\left.(\mathrm{CCFA}-\mathrm{SS})^{2}\right) / \mathrm{kg}$ of $\mathrm{BW}^{3}$

\begin{tabular}{|c|c|c|c|c|c|}
\hline \multirow{2}{*}{ Side injected } & \multicolumn{4}{|c|}{ Treatment group } & \multirow{2}{*}{$P$-value } \\
\hline & \multicolumn{2}{|c|}{ Saline } & \multicolumn{2}{|c|}{ CCFA-SS } & \\
\hline \multicolumn{6}{|l|}{ d 5 or $6(2$ or 3$)$} \\
\hline First & 493 & $99.5 \pm 0.3$ & 496 & $98.3 \pm 1.1$ & 0.070 \\
\hline $\begin{array}{c}\text { Second } \\
\text { d } 14(11)\end{array}$ & 493 & $98.8 \pm 0.7$ & 496 & $96.6 \pm 1.6$ & 0.093 \\
\hline $\begin{array}{l}\text { Second } \\
\text { d } 57 \pm 3(54 \pm 3)\end{array}$ & 478 & $99.1 \pm 0.5$ & 488 & $98.7 \pm 0.7$ & 0.59 \\
\hline First & 453 & $99.8 \pm 0.2$ & 475 & $99.8 \pm 0.1$ & 0.76 \\
\hline Second & 453 & $99.7 \pm 0.2$ & 475 & $99.8 \pm 0.1$ & 0.56 \\
\hline
\end{tabular}

${ }^{1}$ Back-transformed LSM \pm SEM.

${ }^{2}$ Pfizer Animal Health, New York, NY.

${ }^{3}$ Numbers in parentheses are the days between administration of the second dose and the observation.

\section{DISCUSSION}

The results of this clinical trial demonstrate that 2 treatments of CCFA-SS given at the base of the ear $72 \mathrm{~h}$ apart to cows with metritis, as defined by rectal temperature $\geq 39.5^{\circ} \mathrm{C}$ and fetid vaginal discharge, increased the clinical cure rate 19\% compared with saline controls. This increase in clinical cure rate is similar to that demonstrated with ceftiofur administered daily as well as other antibiotic treatments. Chenault et al. (2004) reported a $15 \%$ increase in clinical cure rate compared with controls at $14 \mathrm{~d}$ after 5 daily injections of 2.2-mg CE of ceftiofur hydrochloride/ $\mathrm{kg}$ of $\mathrm{BW}$ in cows enrolled with a rectal temperature $\geq 39.5^{\circ} \mathrm{C}$ and fetid vaginal discharge. Zhou et al. (2001) reported that cure rate was increased $23.3 \%$ by d 10 with 3 -d administration of 1-mg CE of ceftiofur hydrochloride or sodium/ $\mathrm{kg}$ of $\mathrm{BW}$ to cows enrolled with rectal temperature $\geq 39.5^{\circ} \mathrm{C}$ that also had a vaginal discharge at enrollment. Drillich et al. (2001) found that cure rates based on rectal temperature $<39.5^{\circ} \mathrm{C}$ on $\mathrm{d} 6$ for cows with toxic puerperal metritis were similar for treatments of 2.2-mg CE of ceftiofur sodium/ $\mathrm{kg}$ of BW for $3 \mathrm{~d}$ with or without intrauterine antibiotics $(2,500 \mathrm{mg}$ of ampicillin and $600 \mathrm{mg}$ of cloxacillin) and intrauterine antibiotics plus $600 \mathrm{mg}$ of ampicillin i.m. for $3 \mathrm{~d}$. The cure rates of metritis ( 82.9 to $84.8 \%$ ) were numerically higher than those in the present study ( $74.3 \%$ for CCFA-SS).

The effects of CCFA-SS treatment on rectal temperatures during the first 5 or $6 \mathrm{~d}$ of the study were similar to those observed by others. Chenault et al. (2004) reported that rectal temperature was decreased during $5 \mathrm{~d}$ of treatment with either 1.1 or $2.2-\mathrm{mg} \mathrm{CE}$ of ceftiofur hydrochloride $/ \mathrm{kg}$ of $\mathrm{BW}$ and the decrease was approximately $0.9^{\circ} \mathrm{C}$ from d 1 to 5 for both treatments. Smith et al. (1998) observed a $0.7^{\circ} \mathrm{C}$ drop in rec-

Table 4. Numbers of cows with adverse health events (AE) for cows treated with $1.5 \mathrm{~mL}$ of saline $/ 45.5 \mathrm{~kg}$ of BW or 6.6-mg ceftiofur equivalents (CE) of ceftiofur crystalline free acid sterile suspension (CCFA-SS $\left.{ }^{1}\right) /$ $\mathrm{kg}$ of BW

\begin{tabular}{|c|c|c|c|c|}
\hline \multirow[b]{2}{*}{ Event category } & \multicolumn{2}{|c|}{ No. of cows } & \multicolumn{2}{|c|}{ No. of $\mathrm{AE} / \mathrm{cow}$} \\
\hline & Control & CCFA-SS & Control & CCFA-SS \\
\hline Mastitis after $\mathrm{d} 14$ & 20 & 14 & 28 & 19 \\
\hline Pneumonia & 13 & 10 & 15 & 11 \\
\hline Gastrointestinal tract & 10 & 10 & 11 & 10 \\
\hline Foot/leg & 23 & 13 & 25 & 15 \\
\hline Injury & 3 & 9 & 4 & 12 \\
\hline Other & 18 & 8 & 22 & 8 \\
\hline Mean $^{2}$ & $13.9 \pm 2.4$ & $10.6 \pm 2.0$ & $0.13 \pm 0.003$ & $0.10 \pm 0.002$ \\
\hline$P$-value ${ }^{3}$ & \multicolumn{2}{|c|}{0.14} & \multicolumn{2}{|c|}{0.11} \\
\hline
\end{tabular}

${ }^{1}$ Pfizer Animal Health, New York, NY.

${ }^{2}$ Back-transformed LSM \pm SEM for percent of cows that had any AE (yes or no) and for number of AE per cow.

${ }^{3}$ CCFA-SS compared with control for no. of cows or no. of AE/cow. 
tal temperature from $\mathrm{d} 1$ to $\mathrm{d} 5$ for cows treated with 2.2-mg CE of ceftiofur sodium/ $\mathrm{kg}$ of BW i.m. for $5 \mathrm{~d}$. Cows in that study were diagnosed with toxic puerperal metritis based on criteria of rectal temperature $>39^{\circ} \mathrm{C}$, uterine physical condition, fetid vulvar discharge, and depressed milk yield.

No uterine samples were taken to evaluate bacterial population, but the increased clinical cure rate would suggest that concentrations of ceftiofur derivatives were sufficiently high for sufficiently long to reduce metritis defined, in part, by the presence of uterine discharge. Witte et al. (2011) showed that a single injection of CCFA-SS in healthy cows resulted in ceftiofur derivative concentrations in serum and endometrial tissue that were above reported minimum concentrations required to inhibit relevant pathogens such as E. coli and A. pyogenes ( 0.5 and $0.125 \mu \mathrm{g} / \mathrm{mL}$, respectively) over a 7-d period (Okker et al., 2002; Sheldon et al., 2004a; Drillich et al., 2006).

The safety of 2 treatments with CCFA-SS 3 d apart was evaluated by scoring the injection procedure and injection site appearance. Normal restraint and no reinjection were adequate for $\geq 97.1 \%$ of the injections. The injection procedure was further evaluated by observation of the base of the ear immediately after treatment administration. Greater than or equal to $85.8 \%$ of the cows were normal at the site, although some animals had bleeding and leak back of material, and effects were similar for CCFA-SS and for saline.

The safety of CCFA-SS injection was further evaluated by scoring the base of the ear treatment administration sites approximately 1,2 , and 8 wk after the first of the 2 treatments. The average percentages of normal scores during the first and second weeks were approximately 25 and $10 \%$, respectively, lower for the CCFA-SS than saline cows and were higher for the first than the second injection, whereas no differences were observed between treatment and injection during the eighth week. This indicates that even saline administered s.c. in the base of the ear also elicits a site reaction, albeit less than that to CCFA-SS. By 14 or $11 \mathrm{~d}$ after the first or second injection of CCFA-SS, respectively, $79.6 \%$ or more of the sites were normal. The percentages of normal ear carriage scores for both treatments were $\geq 96.6$ throughout the study.

The fact that 1 of the approximately 500 cows given approximately 1,000 injections $(0.1 \%)$ died very soon after administration of CCFA-SS is consistent with the warning on the label for CCFA-SS that injection of CCFA-SS into the arteries of the ear is likely to cause sudden death. This happens at a very low rate and is likely due to inadvertently administering treatment intraarterially.

\section{CONCLUSIONS}

Two doses of CCFA-SS (6.6-mg CE/ $\mathrm{kg}$ of BW) at a 72-h interval provide a safe and effective treatment of acute postpartum metritis in dairy cattle.

\section{ACKNOWLEDGMENTS}

The authors gratefully acknowledge the participation of the following investigators in the conduct of the study described: Scott Abbott (Dairy Veterinary Management, Sunnyside WA), Michael Bossom (DeWitt Veterinary Clinic, DeWitt, IA), Paul Busman (Sparta Animal Clinic, Sparta, MI), Michael Capel (Perry Veterinary Clinic, Geneseo, NY), Robin Carlson (Dalarna Farms, New London, IA), Ricardo Chebel (Caine Veterinary Teaching Center, Caldwell, ID), Kevin Crandall (Rocky Mountain Vet Clinic, Shelley, ID), Geoffrey Dahl (University of Florida, Gainesville), Greg Goodell (The Dairy Authority LLC, Greeley, CO), Breck Hunsaker (Horton Research Center, Caldwell, ID), Niles Jennett (Dairy Vet Services, Chandler, AZ), John Lee (Atwater Veterinary Clinic, Merced, CA), Kenneth Mitchell (Valley Veterinarians Inc., Tulare, CA), Jose Santos (Veterinary Medicine Teaching and Research Center, Tulare, CA), Richard Wallace (University of Illinois, Urbana, IL), and Chad Wright (Vet Outlet, Bakersfield, CA).

\section{REFERENCES}

Bicalho, M., R. Bicalho, and V. Machado. 2011. Association between virulence factors of Escherichia coli, Fusobacterium necrophorum, and Arcanobacterium pyogenes and uterine diseases of dairy cows. J. Dairy Sci. 94(E-Suppl. 1):17. (Abstr.)

Borsberry, S., and H. Dobson. 1989. Periparturient diseases and their effect on reproductive performance in five dairy herds. Vet. Rec. 124:217-219.

Chenault, J. R., J. F. McAllister, S. T. Chester Jr., K. M. Dame, F. M. Kausche, and E. J. Robb. 2004. Efficacy of ceftiofur hydrochloride sterile suspension administered parenterally for the treatment of acute postpartum metritis in dairy cows. J. Am. Vet. Med. Assoc. 224:1634-1639.

Drillich, M., S. Arlt, S. Kersting, A. A. Bergwerff, P. Scherpenisse, and W. Heuwieser. 2006. Ceftiofur derivatives in serum, uterine tissues, cotyledons, and lochia after fetal membrane retention. J. Dairy Sci. 89:3431-3438.

Drillich, M., O. Beetz, A. Pfützner, M. Sabin, H.-J. Sabin, P. Kutzer, H. Nattermann, and W. Heuwieser. 2001. Evaluation of a systemic antibiotic treatment of toxic puerperal metritis in dairy cows. J. Dairy Sci. 84:2010-2017.

FDA-CVM (Food and Drug Administration-Center for Veterinary Medicine). 2001. Guidance for Industry \#85, Good Clinical Practice, VICH GL9, Final Guidance. FDA-CVA, Rockville, MD.

Huszenicza, G., M. Fodor, M. Gacs, M. Kulcsar, M. J. W. Dohmen, M. Vamos, L. Porkolab, T. Kegl, J. Bartyik, J. A. C. M. Lohuis, S. Janosi, and G. Szita. 1999. Uterine bacteriology, resumption of cyclic ovarian activity and fertility in postpartum cows kept in large-scale dairy herds. Reprod. Domest. Anim. 34:237-245.

LeBlanc, S. J., T. F. Duffield, K. E. Leslie, K. G. Bateman, G. P. Keefe, J. S. Walton, and W. H. Johnson. 2002. Defining and diag- 
nosing postpartum clinical endometritis and its impact on reproductive performance in dairy cows. J. Dairy Sci. 85:2223-2236.

Okker, H., E. J. Schmitt, P. L. A. M. Vos, P. Scherpenisse, A. A. Bergwerff, and F. H. Jonker. 2002. Pharmacokinetics of ceftiofur in plasma and uterine secretions and tissues after subcutaneous postpartum administration in lactating dairy cows. J. Vet. Pharmacol. Ther. 25:33-38.

Overton, M., and J. Fetrow. 2008. Economics of postpartum uterine health. Pages 39-43 in Proc. Dairy Cattle Reprod. Council Convention, Omaha, DE. Dairy Cattle Reprod. Council, Hartland, WI.

SAS Institute. 2003. SAS/STAT User's Guide. Version 9.1.3. SAS Institute Inc., Cary, NC.

SAS Institute. 2009. SAS/STAT User's Guide. Version 9.2. SAS Institute Inc., Cary, NC.

Sawant, A. A., B. M. Sordillo, and L. M. Jayarao. 2005. A survey of antibiotic usage in dairy herds in Pennsylvania. J. Dairy Sci. 88:2991-2999.

Sheldon, I. M., M. Bushnell, J. Montgomery, and A. N. Rycroft. 2004a. Minimum inhibitory concentrations of some antimicrobial drugs against bacteria causing uterine infections in cattle. Vet. Rec. 155:383-387.

Sheldon, I. M., G. S. Lewis, S. LeBlanc, and R. O. Gilbert. 2006. Defining postpartum uterine disease in cattle. Theriogenology 65:1516-1530.

Sheldon, I. M., A. N. Rycroft, and C. Zhou. 2004b. Association between postpartum pyrexia and uterine bacterial infection in dairy cattle. Vet. Rec. 154:289-293.
Smith, B. I., G. A. Donovan, C. Risco, R. Littell, C. Young, L. H. Stanker, and J. Elliott. 1998. Comparison of various antibiotic treatments for cows diagnosed with toxic puerperal metritis. J. Dairy Sci. 81:1555-1562.

Stevenson, J. S., and E. P. Call. 1988. Reproductive disorders in the periparturient dairy cow. J. Dairy Sci. 71:2572-2583.

Wittrock, J. M., K. L. Proudfoot, D. M. Weary, and M. A. G. von Keyserlingk. 2011. Short communication: Metritis affects milk production and cull rate of Holstein multiparous and primiparous dairy cows differently. J. Dairy Sci. 94:2408-2412.

Witte, T. S., M. Iwersen, T. Kaufmann, P. Scherpenisse, A. A. Bergwerff, and W. Heuwieser. 2011. Determination of ceftiofur derivatives in serum, endometrial tissue, and lochia in puerperal dairy cows after subcutaneous administration of ceftiofur crystalline free fatty acid. J. Dairy Sci. 94:284-290.

Zhou, C., J. F. Boucher, K. J. Dame, M. Moreira, R. Graham, J. Nantel, S. Zuidhof, L. Arfi, R. Flores, G. Neubauer, and J. Olson. 2001. Multilocation trial of ceftiofur for treatment of postpartum cows with fever. J. Am. Vet. Med. Assoc. 219:805-808.

Zwald, N. R., K. A. Weigel, Y. M. Chang, R. D. Welper, and J. S. Clay. 2004. Genetic selection of health traits using producerrecorded data. I. Incidence rates, heritability estimates, and sire breeding values. J. Dairy Sci. 87:4287-4294. 